\section{Respiratory Symptoms and Skin Irritation Among Hospital Workers Using a New Disinfection Product - Pennsylvania, 2015}

Brie Hawley, $\mathrm{PhD}^{1}$; Megan L. Casey, $\mathrm{MPH}^{1}$; Jean M. Cox-Ganser, $\mathrm{PhD}^{1}$; Nicole Edwards, MS ${ }^{1}$; Kathleen B. Fedan ${ }^{1}$; Kristin J. Cummings, MD ${ }^{1}$

In March 2014, a new disinfection product, consisting of hydrogen peroxide, peroxyacetic acid, and acetic acid, was introduced at a Pennsylvania hospital to aid in the control of health care-associated infections. The product is an Environmental Protection Agency-registered non-bleach sporicide advertised as a one-step cleaner, disinfectant, and deodorizer. According to the manufacturer's safety data sheet, the product requires no personal protective equipment when it is diluted with water by an automated dispenser before use. On January 30, 2015, CDC's National Institute for Occupational Health (NIOSH) received a confidential employee request to conduct a health hazard evaluation at the hospital. The request cited concerns about exposure of hospital environmental services staff members to the product and reported symptoms among persons who had used the product that included eye and nasal problems, asthma-like symptoms, shortness of breath, skin problems, wheeze, chest tightness, and cough.

In response to the request, NIOSH gathered information by telephone and e-mail in February and March and visited the hospital on April 9 to inform the design of an air sampling evaluation and health interview questionnaire. Pilot air sampling was conducted on July 29, including the collection of full-shift, time-weighted average personal air samples from five workers for measurement of hydrogen peroxide, acetic acid, and peroxyacetic acid.

During August 31-September 3, NIOSH interviewed 79 (78\%) of 101 current environmental services staff members about their health. Among the 79 interviewees, 68 (86\%) reported using the product; the interview responses of these 68 staff members were analyzed. Asthma-like symptoms were defined using a set of validated questions (1). Work-related symptoms were defined as symptoms that improved when the worker was away from the facility on days off or on vacation. During September 8-11, $\mathrm{NIOSH}$ collected 45 additional full-shift personal air samples for measurement of hydrogen peroxide, acetic acid, and peroxyacetic acid. Exposure assessment results from July and September were combined for a total convenience sample of 50 workers.

The most commonly reported health outcomes were watery eyes (46\%), nasal problems (41\%), asthma-like symptoms $(28 \%)$, use of allergy medicine (16\%), and shortness of breath
(16\%) (Table). Thirty (44\%) workers reported at least one workrelated health outcome, most commonly watery eyes $(29 \%)$ or nasal problems (22\%). Among 10 respondents with self-reported physician-diagnosed asthma, six reported that something at work brought on or worsened their asthma, and three mentioned the disinfection product. Full-shift air sample results for hydrogen peroxide ranged from 6 parts per billion (ppb) to $511 \mathrm{ppb}$; for acetic acid, from $7 \mathrm{ppb}$ to $530 \mathrm{ppb}$; and for peroxyacetic acid, from $1 \mathrm{ppb}$ to $48 \mathrm{ppb}$. All measurements for hydrogen peroxide and acetic acid were below their respective occupational exposure limits of 1,000 ppb and 10,000 ppb (2). No full-shift exposure limit has been established for peroxyacetic acid.

Few assessments of worker exposure to hydrogen peroxide, acetic acid, and peroxyacetic acid in health care settings have been conducted, despite the use of this product in more than 500 hospitals nationally. Two previous investigations conducted by the Occupational Safety and Health Administration at hospitals in Pennsylvania (3) and Vermont (Karl Hayden, Safety/Health Compliance Officer, personal communication, Vermont Department of Labor, 2015), in response to employee concerns about symptoms reported while using this product, were limited to air sampling; no health assessments were performed. In the CDC evaluation, environmental services staff members reported work-related symptoms despite measured exposures that were below the established full-shift exposure limits for hydrogen peroxide and acetic acid. However, because both hydrogen peroxide and peroxyacetic acid are strong oxidants, it is possible that the mixture of hydrogen peroxide and peroxyacetic acid contributed to the symptoms reported by workers. Furthermore, existing exposure limits might not be protective against asthma-like symptoms. The Association of Occupational and Environmental Clinics recently listed this product as an asthmagen in its Exposure Database (4).

These results are preliminary and further investigation is needed to fully understand the relationship between exposure to disinfection products in health care settings and worker health. In the interim, consideration of the health and safety of workers is prudent when choosing disinfection products, and hospitals should be alert for respiratory, skin, and eye symptoms in environmental services staff members. Hospital management can implement a reporting system that would permit employees to report work-related symptoms, with the option for employees to remain anonymous. If environmental services staff members report respiratory, skin, and/or eye symptoms, a combination of engineering and administrative controls could be needed to reduce employee exposures. In addition, physicians should be 
aware of the potential adverse health effects of occupational exposure to cleaning and disinfection products when evaluating patients with respiratory and skin symptoms (5).

Although a one-step cleaner, disinfectant, and deodorizer might be considered for widespread use in a hospital, the decision to use particular disinfection products in specific areas of a health care facility should reflect the level of risk for a health care-associated infection. The NIOSH Health Hazard Evaluation program (http://www.cdc.gov/niosh/hhe/) can assist hospitals and public health departments in the investigation of potential health effects related to exposures in a health care setting.

TABLE. Prevalence of symptoms and work-related symptoms among hospital environmental services staff members reporting use of a new disinfection product $(\mathrm{N}=68)$ - Pennsylvania, AugustSeptember 2015

\begin{tabular}{lcc}
\hline Symptom & $\begin{array}{c}\text { Reported } \\
\text { symptoms } \\
\text { No. (\%) }\end{array}$ & $\begin{array}{c}\text { Reported work- } \\
\text { related symptoms* } \\
\text { No. (\%) }\end{array}$ \\
\hline Watery eyes $^{\dagger}$ & $31(46)$ & $20(29)$ \\
Nasal problems & \\
Asthma-like symptoms $^{\S}$ & $28(41)$ & $15(22)$ \\
Shortness of breath $^{\dagger}$ & $19(28)$ & $10(15)$ \\
Skin problems $^{\dagger}$ & $11(16)$ & $5(7)$ \\
Wheeze $^{\dagger}$ & $10(15)$ & $7(10)$ \\
Chest tightness $^{\dagger}$ & $10(15)$ & $5(7)$ \\
Cough $_{\text {Asthma attack }}^{\dagger}$ & $9(13)$ & $2(3)$ \\
\hline
\end{tabular}

* Defined as a symptom that improved away from the facility, either on days off or on vacation.

† During the past 12 months.

$\S$ Defined as current use of asthma medicine or one or more of the following symptoms in the last 12 months: wheezing or whistling in the chest, awakening with a feeling of chest tightness, or attack of asthma.

\section{Acknowledgments}

Participating hospital staff members; Michael Beaty, Randy Boylstein, Matt Duling, Ethan Fechter-Leggett, Reid Harvey, Alyson Johnson, Robert B. Lawrence, Tia McClelland, Christopher Mugford, Randall Nett, Anand Ranpara, Marcia Stanton, M. Abbas Virji, and Sandy White, National Institute for Occupational Safety and Health.

${ }^{1}$ Respiratory Health Division, National Institute for Occupational Safety and Health, CDC, Morgantown, West Virginia.

Corresponding author: Brie Hawley, 304-285-6071, ygd2@cdc.gov.

\section{References}

1. Grassi M, Rezzani C, Biino G, Marinoni A. Asthma-like symptoms assessment through ECRHS screening questionnaire scoring. J Clin Epidemiol 2003;56:238-47. http://dx.doi.org/10.1016/ S0895-4356(02)00613-3

2. National Institute for Occupational Safety and Health (NIOSH). Pocket guide to chemical hazards. DHHS (NIOSH) publication no. 2010-168c. Atlanta, GA: US Department of Health and Human Services, CDC, NIOSH. http://www.cdc.gov/niosh/npg/

3. Occupational Safety and Health Administration. Inspection no. 1019738. Region 3. Pittsburgh, PA: Occupational Safety and Health Administration; 2015.

4. Association of Occupational and Environmental Clinics. Comprehensive Occupational \& Environmental Exposure Database; 2015. http://www. aoecdata.org/ExpCodeLookup.aspx

5. Quinn MM, Henneberger PK; National Institute for Occupational Safety and Health (NIOSH), National Occupational Research Agenda (NORA) Cleaning and Disinfecting in Healthcare Working Group. Cleaning and disinfecting environmental surfaces in health care: toward an integrated framework for infection and occupational illness prevention. Am J Infect Control 2015;43:424-34. http://dx.doi.org/10.1016/j.ajic.2015.01.029 